\title{
Surveying Persons in Same-Sex Relationships in a Probabilistic Way - An Example from the Netherlands
}

\author{
Stephanie Steinmetz ${ }^{1}$ and Mirjam Fischer ${ }^{2}$
}

\begin{abstract}
In the last decade, the call for improved estimates of lesbians, gay men and bisexual (LGB) populations has grown steadily. This is related to the increasing visibility of same-sex unions and the rapidly evolving changes in the legal and normative institutional frameworks regarding same-sex relationships in Western countries. The aim of this article is to present the sampling strategy and discuss the quality of a recently conducted probability-based survey in the Netherlands that targeted mixed-sex and same-sex couples with and without children. The core questions addressed are (1) whether the sampling strategy paid off in terms of identifying same-sex households and (2) whether the collected sample is representative of the target population. While the sampling strategy has success in identifying same-sex households, the question of representativeness remains a challenging task in surveying LGB populations and couples in particular. Especially, aspects related to the sampling strategy, the survey mode and the covered topic of the research are central to understanding observed selection patterns in the examined mixed- and same-sex samples.
\end{abstract}

Key words: Sampling LGB populations; sampling same-sex couples; selection biases, representativeness; probability-based sampling.

\section{Introduction}

In the last decade, the call for improved estimates of lesbians, gay men and bisexual (LGB) populations has grown steadily (Valfort 2017; OECD 2019). This is related to the increasing visibility of same-sex unions and the rapidly evolving changes in the legal and normative institutional frameworks regarding sexual diversity in Western countries. While the study of LGB persons in general, and same-sex couples in particular, has a strong tradition in qualitative methodological approaches (e.g., Barrett and Tasker 2001; Goldberg and Allen 2007; Hicks 2005; Patterson 1992), scholars continuously make efforts to overcome methodological challenges associated with the quantitative study of this population (Umberson et al. 2015). A prominent challenge in this regard is the establishment of a large representative sample of the LGB population by means of probability sampling.

${ }^{1}$ University of Lausanne, Institute for Social Sciences, Quartier UNIL-Mouline, Batiment Géopolis, 1015 Lausanne, Switzerland. Email: Stephanie.Steinmetz@unil.ch

2 German Institute for Economic Research (DIW Berlin), Survey Methodology and Survey Management (SOEP Survey), Möhrenstraße 58, 10117 Berlin, Germany. Email: mfischer@diw.de

Acknowledgments: The UNICON project was funded by the Amsterdam Centre for Inequality Studies (AMCIS); the research group Institutions, Inequalities and Life courses (IIL) at the University of Amsterdam; Fonds Stimulering en Ontwikkeling by the Nederlandse Vereniging voor Seksuologie (NVVS) and the ERC project 'Family complexity' by Matthijs Kalmijn (FP7/2007-2013 / ERC grant agreement no. 669334). 
By addressing the question how LGB populations can be sampled (considering LGBs as one group (persons in same-sex couples), which we compare to the population of persons in same-sex couples), the aim of this article is twofold. First, we want to know how well a recent probability-based survey in the Netherlands did in terms of identifying households where same-sex couples with and without children live (Unions in Context Study (UNICON); Fischer et al. 2017). Second, we want to know to what extent the collected sample is representative of the target population of partnered LGBs in the Netherlands. To this end, we use two available probability-based national surveys, the Netherlands Longitudinal Life Course Study (NELLS, Tolsma et al. 2014) and the Dutch Safety Monitor (VM), as benchmarks for the comparison of core socio-demographic characteristics of both mixed- and same-sex couples. The article contributes to the debate on how a specific subset of the LGB population, namely persons in same-sex relationships, can be sampled in a probabilistic and efficient way, leading to surveys which allow for reliable estimation of statistical parameters.

\section{Challenges of Studying LGBs and Persons in Same-Sex Relationships in a Probabilistic Manner}

Until the 1990s, convenience (non-probability) samples dominated research on LGB populations (see, for example in the United States, Kinsey et al. 1948; Bell and Weinberg 1978). And even though with the onset of the HIV/AIDS crisis in the early 1980s in the United States, several large probability-based population surveys started to include measures of sexual orientation, in particular health surveys in the United States and Europe (Galupo et al. 2016; Laumann et al. 1994; Spira et al. 1994; Wellings et al. 1994; Wolff et al. 2017), they remain often limited in scope (health, victimization or LGBspecific topics) and target population (only LGBs). This makes the type of substantive knowledge we have about LGB populations rather narrow.

As underlined by the study of the Institute of Medicine Committee on Lesbian, Gay, Bisexual and Transgender Health Issues (2011), there are three important challenges when trying to collect data on LGB populations in general and same-sex couples in particular: (1) defining and measuring sexual orientation, (2) overcoming the reluctance of some LGB individuals to identify themselves to researchers, and (3) obtaining high-quality samples of relatively small population segments.

One of the continuously discussed issues when collecting data on LGB populations is the optimal strategy of measuring sexual orientation (e.g., Almazan et al. 2009; Haseldon and Joloza 2009). Commonly measured dimensions of sexual orientation include selfassignment to identity labels (lesbian, gay, bisexual, etc.) or same-sex attraction and behavior (dating or sexual) (e.g., Dewaele et al. 2014; Meyer and Wilson 2009). While self-identification is often applied in topical surveys (in particular health-related surveys), an alternative measurement strategy that is frequently applied in bigger cross-national and/ or multi-disciplinary surveys is the identification of LGBs via the self-reported gender and the self-reported relationship between two respondents of a household (partnership inference). The strategy of partnership inference to measure sexual orientation in such surveys bears great potentials in terms of topic coverage and cross-national comparisons, yet it only covers the partnered subset of the LGB population. 
A further challenge is related to the sensitivity of the topic (such as sexual orientation, income, etc.) and the reluctance of some participants to disclose accurate information about themselves. In the case of sexual minorities, the disclosure bias might be generally related to privacy concerns or, more particularly, to avoid stigma and discrimination. When confronted with such a sensitive question, respondents may decline to answer or may intentionally give an inaccurate response (item nonresponse). In some cases, respondents may decide not to participate in the study at all (nonparticipation), thereby reducing the overall response rate and possibly making the sample less representative of the larger population. All of these outcomes have important implications for data quality (Lee 1993; Tourangeau and Yan 2007) as those who do not disclose their sexual orientation accurately, or decline to participate altogether, differ in relevant ways from those who do disclose and participate. Besides the importance of the cultural competence of the researcher studying hard-to-survey populations (e.g., Dillman et al. 2009; Tourangeau 2014), a number of techniques have been used to improve response rates to questions relating to sensitive topics. For instance, modes of data collection (such as the web) that foster participants' sense of confidentiality or anonymity may yield higher rates of disclosure (e.g., Valfort 2017; Villarroel et al. 2006).

Finally, as indicated by Meyer and Wilson (2009), as well as by Binson et al. (2007), careful sampling begins with the ability to enumerate (i.e., identify and count) the population of interest. If a population can be easily enumerated, it can be sampled in a fairly straightforward manner. However, sampling LGB populations is a challenging endeavor as they are what survey methodologists would describe as 'hard-to-survey' (Tourangeau 2014; Sudman et al. 1988; Solarz 1999). In particular, probability-based sampling presents an obstacle as there is no conceivable list of every LGB person or samesex couple in a country that could serve as a sampling frame. As a consequence, it is hard to sample LGB respondents randomly (screening presents the only option, but this procedure is very costly and ineffective). Instead, research often relies on non-probability (convenience) sampling, which is problematic in terms of representativeness. For instance, studies that rely on (on- or offline) advertisement strategies to recruit respondents have persistent problems with the non-representativeness of their samples. This is due to the fact that volunteering for a survey - in particular an online survey - is often done by a rather selective group in terms of socio-demographic characteristics and motivations (Bolding et al. 2007; Meyer and Colten 1999; Rosser et al. 2009). For example, studies conducted among men who have sex with men based on web surveys for the United States and the United Kingdom found that certain variables were associated with higher rates of questionnaire noncompletion, such as nonwhite ethnicity, concealment of sexual orientation, self-identifying as heterosexual or bisexual, and in some cases, younger age (Evans et al. 2008; Ross et al. 2004). A further drawback of these studies is that they only focused on LGBs without including heterosexuals as a comparison group (European Union Agency for Fundamental Rights 2012 or for the United States, see Herek et al. 2010). As a consequence, findings based on such data are not comparative and cannot be generalized to a broader target population. In fact, such studies rather provide insights into very specific LGB subgroups, like persons who are recruited via health facilities, subscribers to certain magazines or visitors of LGB party venues. It is obvious that these subgroups may differ from the general LGB population with respect to health issues (when 
recruited via health facilities) or a more outgoing lifestyle (when recruited at party venues). Researchers who want to generalize their findings to the population they are researching are in need of probability samples and appropriate sampling frames. In this respect, the use of population registers and census data to identify officially registered partnerships can be appealing (e.g., Andersson et al. 2006; Schwartz and Graf 2009 for the United States). Registers have the advantage that they provide a list of a country's entire population of officially registered same-sex couples (married or in a civil union). This can serve as sampling frame for a random sample, or the entire population can be analyzed. The large number of observations offers promising possibilities for quantitative studies of same-sex couples. The drawback of register data is that the range of phenomena that can be studied is often limited (for example to demographic information, such as income, employment and living situation) compared to social surveys, which cover larger thematic areas. Moreover, LGBs in register data constitute a selective group, namely those who are married to or in a civil union with a partner of the same sex. Cohabiting same-sex couples who are not married or in a civil union cannot be reached in this way.

When looking for probability-based large-scale surveys, which allow for the identification of LGBs (either in a direct or indirect way), the options tend to be limited and often tailored towards topics such as victimization, health and lifestyle. When searching for broader probability-based social survey data covering LGB populations in Europe, for instance, only two large-scale surveys come to the fore: the European Social Survey, ESS (2018), (http://www.europeansocialsurvey.org/) and the Generations and Gender Programme (GGS Waves 1, and 2, http://www.ggp-i.org/). These surveys allow for an indirect identification of the LGB population via partnership inference. A big drawback of population-based probability surveys is that in such data, the proportions of men and women who identify as non-heterosexual are often small - around 1\% (Rothblum 2007). On the one hand, this creates statistical power issues for the estimation of reliable parameters. On the other hand, otherwise harmless mistakes, such as recording errors (e.g., recording one partner's gender wrong and hence misclassifying the couple), can cause distorted findings in the numerically small group (see Banens and Le Penven 2016; Cortina and Festy 2014; DeMaio et al. 2013; Fischer 2016; Regnier-Loilier 2018).

\section{Targeting Cohabiting Same-Sex Couples in the Netherlands - The UNICON Project}

Given the lack of quality representative survey data on the LGB population and persons in same-sex relationships (OECD 2019), the UNICON project collected representative survey data among lesbian, gay and heterosexual couples and families in the Netherlands in 2016. In particular, it aimed at creating a carefully crafted data set, which (1) purposely includes persons in same-sex couples in a sampling frame, (2) uses a random sample, (3) oversamples persons in same-sex couples to achieve a large number of observations, (4) includes a suitable comparison group of persons in mixed-sex couples, and (5) covers a wide range of LGB-specific and more general topics (see Fischer et al. 2017). Note that the joint study of LGB and heterosexual respondents poses unique challenges in terms of the framing of the study to potential respondents. However, in order to study structural 
disadvantage along sexual orientation lines, it is indispensable to study both groups jointly (Umberson et al. 2015; Valfort 2017). Therefore, the UNICON data is unique in the way it incorporates both LGB and heterosexual respondents and covers both general and LGB-specific topics.

\subsection{Sampling Design}

For the project, a two-stage sampling design was used. Firstly, 36 municipalities were selected that vary in size, degree of urbanization and geographical region. The Netherlands is divided into 380 administrative units in 2016 - the municipalities. Often a municipality equals a large city and its suburbs. Outside the highly urbanized areas, a municipality typically encompasses multiple smaller towns or a cluster of villages. The stratified selection of municipalities is important, given the stark differences regarding population size, ranging from more than 840,000 inhabitants in Amsterdam to just short of 1,000 in the smallest municipality (Statistics Netherlands 2018). The municipality selection for the UNICON study was based on a different survey, the NELLS, which has sampled the municipalities according to an urbanization- and region-stratified sampling method (De Graaf et al. 2010). The UNICON is based on the same sample of municipalities in order to allow a joint study of the two surveys. This provides many advantages, such as obtaining detailed data on attitudes toward gender and family values and homosexuality from the NELLS to study individual-level phenomena in the UNICON in relation to the attitudinal context (see Fischer 2019). The stratified municipality sample ensures geographic distribution and variation in the way people think about topics such as homosexuality (Kuyper 2016).

Secondly, the local authorities in each municipality were contacted by a phone call inviting them to cooperate with the research project and follow-up letters with detailed information about the project. In the Netherlands, municipalities can decide whether they want to cooperate with scientific institutes by sharing information from the population registers. Those municipalities which agreed to participate proceeded to draw a random sample of households from their registers. The sample of households was stratified according to three household types: (1) cohabiting mixed-sex couple households, (2) cohabiting same-sex couple households without children, and (3) cohabiting same-sex couple households with children. The main motivation for choosing these groups was the intent to oversample same-sex couple households, in particular those with children, so that the group would be large enough to make statistical comparisons between them. For mixed-sex couples, it could be expected that a substantial share would have children without making this an explicit sampling criterion. Among same-sex couples, however, the groups have been differentiated, since same-sex couples have children far less often than mixed sex couples (Andersson et al. 2006; Gates 2013; Kuyper 2016).

Based on the Dutch population registers, it is possible to identify persons who are in legally registered unions, such as marriage or civil partnerships. As the aim of the project was to include all couples, also those who cohabitate without being married or in a civil union, an approximation strategy was applied. That is, we used a number of known characteristics from the registers in order to make an estimate of households where it is likely that couples live. The list of these approximated households then 
served as the list of addresses (the population of interest) from which the probability sample was drawn.

We approximate couple households in the following manner: we selected households where two persons live, who (1) are between the age of 30-65; (2) are of the same or different sex, (3) do not have a parent-child relation with each other, (4) are not each other's siblings, and (5) live with a child under the age of 18. The age limit was implemented in order to avoid contacting respondents who are (a) not in our target group (i.e., student households where young people of the same sex often live together as flat mates rather than romantic partners) and (b) who are less likely to participate in web mode surveys (i.e., persons older than 65 years). We deemed this strategy appropriate in order to maximize the final sample size given limited financial funds of the project. Criteria 3 and 4 were central to ensuring that two persons were likely a cohabiting couple. For type 3 households - same-sex couples with children - the last criterion (5) applies. We intentionally did not rely on registered parent-child relationships in order to allow for (legally) complex parenthood constellations among same-sex parents to be captured.

The contact with respondents was established by sending a letter to each household with an invitation for both partners in the couple to participate in our web survey. We decided to not feature the LGB topic prominently in the invitation letter to the participants. Instead, we emphasized diversity in living arrangements and families in the hope that this would be attractive enough for same-sex couples to feel encouraged to take part, while reducing possible threats to (selective) response for the mixed-sex couples. In the survey, we confirmed whether the contacted persons were indeed a couple. To enhance the response rate among same-sex couple households - the main target group in this study - they received incentives entailing a prepaid voucher worth EUR 5 for a popular Dutch online retailer. Depending on participation, households received up to three reminders via mail over the course of multiple weeks (Fischer and Steinmetz 2018).

\subsection{Did the Sampling Strategy Pay Off in Terms of Reaching the Target Population?}

Twenty-two municipalities of the 36 municipalities provided a sample of addresses from their population registers for the UNICON study. This translates to a total of 22 participating municipalities and a response rate of $61 \%$ at the municipality level. The final sample is based on 20 municipalities under exclusion of two with too low participation. Table 1 shows the distribution of the realized sample. The numbers in parentheses show the number of municipalities that was sampled. What stands out is the observation that almost all strongly urban municipalities that were sampled also participated, whereas participation was lower in the marginal and moderate ones. This is likely related to the fact that larger municipalities are used to receiving research proposals like ours and they have the capacity to handle them quickly. Smaller municipalities sometimes do not have a statistics department and have to spend more time and resources into fulfilling such a request. There are no notable patterns regarding the regional nonresponse among municipalities.

At the individual level, the UNICON data collected information of 1,353 individual respondents (in 880 households), including 510 persons in mixed-sex couples and 843 persons in same-sex couples. Of those 843 persons in same-sex couples, 267 indicated that 
Table 1. Distribution of the realized sample of municipalities in the UNICON survey; original sample in parentheses.

\begin{tabular}{l|ccc|c}
\hline \multirow{2}{*}{ Region } & \multicolumn{3}{|c|}{ Degree of urbanization } & \multirow{2}{*}{ Total } \\
\cline { 2 - 4 } & marginal & moderate & strong & \\
\hline \multirow{2}{*}{ North/East } & 2 & 3 & 1 & 6 \\
West & $(3)$ & $(4)$ & $(3)$ & $(10)$ \\
South & 1 & 2 & 6 & 9 \\
& $(3)$ & $(4)$ & $(10)$ & $(17)$ \\
& 1 & 0 & 4 & 5 \\
Total & $(3)$ & $(4)$ & $(2)$ & $(9)$ \\
& 4 & 5 & 11 & 20 \\
& $(9)$ & $(12)$ & $(15)$ & $(36)$ \\
\hline
\end{tabular}

they lived with one or more children. Same-sex households with children were almost exclusively women. The response rate at the household level was $24.5 \%$. It was highest among same-sex households with children (34\%), followed by same-sex households without children $(27 \%)$ and mixed-sex households (20\%). This is likely a reflection of the topic of the survey, which was advertised as a study about diversity in living arrangements. These differences can be observed in all three geographical regions (see Fischer et al. 2017). In municipalities of moderate urbanization, same-sex couples had a slightly lower response than mixed-sex couples. In all other municipalities, same-sex couples participated more often. This is in line with another Dutch study among lesbian and heterosexual parents in the Netherlands, which uses a wide range of recruitment strategies, and also observed a higher response among lesbian families compared to heterosexual families (Bos 2004). The overall participation was highest in the North/East (27\%), followed by the West (23\%) and the South (21\%). Overall, the response rate in the UNICON is modest, yet reasonable for a web-based survey in times of declining response rates and survey fatigue. Even a response rate below $10 \%$ is not uncommon for web surveys (Conrad et al. 2010; Lozar Manfreda et al. 2008; Munoz-Leiva et al. 2010; Shih and Fan 2008; Smyth and Pearson 2011).

As indicated, it was possible (but not strictly required) for both partners in the household to respond to our survey. In half of the cases, we do have information from both partners. As the sample was stratified by region and degree of urbanization, and the obtained sample sizes and response rates varied from municipality to municipality, weights were constructed to make the sample nationally representative. To do so, we first obtained from Statistics Netherlands the population of couples in each combination of region and urbanization separately for the three types of couples (mixed-sex, same-sex without children, same-sex with children).

To answer the question whether our approximation strategy was successful in identifying the target population, we calculated the accuracy of the sampling strategy. Table 2 shows how many households that were sampled as one of the three household types confirmed their status in the survey. The calculations show that $99.1 \%$ of the households that were sampled as mixed-sex couples via the approximation strategy turned 
Table 2. Sampled from registers (expected) and respondent self-reports (observed).

\begin{tabular}{lccc}
\hline & \multicolumn{3}{c}{ Expected } \\
\cline { 2 - 4 } Observed & $\begin{array}{c}\text { Household type 1 } \\
\text { Mixed-sex with and } \\
\text { without children }\end{array}$ & $\begin{array}{c}\text { Household type 2 } \\
\text { Same-sex without } \\
\text { children }\end{array}$ & $\begin{array}{c}\text { Household type 3 } \\
\text { Same-sex with } \\
\text { children }\end{array}$ \\
\hline Mixed-sex with and & $\mathbf{3 1 7}$ & 20 & 5 \\
without children & $(\mathbf{9 9 . 1 \% )}$ & $(4.4 \%)$ & $(3.6 \%)$ \\
Same-sex without & 1 & $\mathbf{3 5 2}$ & 3 \\
children & $(0.3 \%)$ & $\mathbf{( 7 8 . 2 \% )}$ & $(2.1 \%)$ \\
Same-sex with & 0 & 38 & $\mathbf{1 3 0}$ \\
children & $(0.0 \%)$ & $(8.4 \%)$ & $\mathbf{( 9 2 . 9 \% )}$ \\
Single & 2 & 40 & 2 \\
& $(0.6 \%)$ & $(8.9 \%)$ & $(1.4 \%)$ \\
\hline
\end{tabular}

Note: Single $=$ respondent without a partner. Calculations based on $\mathrm{N}=923$ households in 19 municipalities as one municipality did not want to include the household type in the sample and could therefore not be included in this calculation.

out to be mixed-sex couples. Among same-sex households with children the accuracy was high $(92.9 \%)$. The approximation strategy was somewhat weaker for same-sex households without children, where the accuracy lies at $78.2 \%$.

A number of households that were sampled as same-sex households without children turned out to be same-sex couples with children (8.4\%) and they remain in the dataset. This relatively high number of children in households where we did not expect them may further point towards the fact that parenthood in same-sex couples can be legally complex. An equally large number of households turned out to be singles of the same sex who share a household but who have not reported a romantic relationship with each other. Our lower age bound of 30 is not a foolproof criterion for excluding shared flats, as young working professionals often remain in these living situations well into their thirties (Kenyon and Heath 2010). Finally, between $3 \%$ and $4 \%$ of the couples that have been sampled as samesex couples with and without children turned out to be mixed-sex couples. Registration mistakes at the municipality level are one possible explanation. Another could be that people deliberately provide false information to the authorities in order to creatively navigate the extremely tensed housing market. All these cases come from highly urban areas, which makes such an explanation plausible.

Overall, the applied approximation strategy to identify same-sex couple households in the register data proved to be successful in obtaining a sizable group of same-sex households. The proposed research design payed off and proved to be an innovative strategy to create a sampling frame for a population, for which creating a sampling frame is otherwise simply not possible. As such, the UNICON data are an advancement in collecting probability-based survey data for LGB populations. It is the biggest probabilitybased survey on same-sex couples and families, which allows studying a broad range of topics (such as well-being, social integration and relationship quality) in comparison with heterosexual couples in the Netherlands. As previously stated, this comparative aspect is crucial when trying to reveal the structural inequality of one social group in comparison with the majority. 


\section{Evaluating the Selectivity and Representativeness of the Collected Sample}

To evaluate the question of representativeness of the collected data, it would be ideal to compare characteristics of the collected survey data to those in the population. However, as previously discussed, the availability of probability data on persons in same-sex relationships and LGBs is limited in the Netherlands and elsewhere (OECD 2019). Hence, it is nearly impossible to find an existing representative data source that includes LGBs in the Netherlands that could be used as benchmark for our comparison. This illustrates again the important gap that the UNICON survey addresses for LGB studies in the Netherlands.

We have applied two strategies, which can give us some insights on the representativeness of the UNICON data. First, we considered the survey, which formed the basis for the municipality selection (NELLS) and compared the respondents in mixedsex couples to each other. Second, we use the only nationally representative survey in the Netherlands that allows the identification of partnered LGBs to compare them to the persons in same-sex relationships in the UNICON.

The former is an attempt at evaluating how well the UNICON reached one of our three target groups, namely persons in mixed-sex couples. The latter comparisons is an attempt to examine this LGB-specific response obstacles more directly. Here, the respective ways of identifying persons in same-sex relationships differ, which is not ideal. Yet, the totality of these comparisons can provide an initial sense of how representative the UNICON data might be, in the absence of true population data. In the following, we elaborate on these two national benchmark surveys we used for the comparison and our analytical strategy.

\subsection{Two National Benchmark Surveys}

First, we turned to the NELLS in order to compare demographic characteristics of persons in mixed-sex couples. The NELLS is a nationally representative, large-scale survey of the Dutch population aged 15-45 (for more details, see De Graaf et al. 2010). It was conducted between December 2008 and May 2010, partly through face-to-face interviews and partly through self-completion questionnaires. The data contain information on 5,312 individuals from 35 municipalities in the Netherlands. The survey yielded an overall response of 52\%. The comparison with the NELLS is an obvious choice, since the selection of municipalities in the UNICON is based on the municipality sample of the NELLS. It is therefore possible to use the two surveys for comparing respondents within the same municipalities. Another advantage of this comparison is the fact that persons in mixed-sex relationships were identified in the same way in both surveys, namely by means of partnership inference (i.e., the combination of the respondent's own gender and the gender of the partner reported by the respondent). One drawback is that the age range covered in the NELLS (15-45 years) and the UNICON (30-65 years) only overlaps by 25 years. Therefore, we were forced to limit our comparison to persons in mixed-sex relationships between the ages of 30 and 45 years.

Second, we used data from the Dutch Safety Monitor (VM, pooled annual data 2012-2015) for the comparison between persons in same-sex relationships. The VM is an annual large-scale survey among individuals aged 15 years and older focusing on various aspects related to safety, experiences of violence, and crime. The nationally representative survey covers many observations, with a minimum of 65,000 respondents annually. 
Response rates typically lie at $44 \%$ and the questionnaires of the VM are primarily completed online (Statistics Netherlands 2016). If respondents do not participate right away, they receive a reminder via mail that includes the option to complete a paper and pencil version of the questionnaire. The VM is among the only representative surveys in the Netherlands that allows an identification of LGBs via self-reported sexual attraction. In order to render the surveys as comparable as possible, we have included a number of restrictions on the VM data. We selected respondents who were married or in a civil union to ensure that we are dealing with partnered persons. We also restricted the sample to those who reported same-sex attraction. Respondents who indicated that they are attracted to both sexes could be in mixed-sex relationships. Of course, this risk remains a possibility also with those reporting same-sex attraction since the different dimension of sexual orientation - identity, attraction and behavior - do not necessarily overlap (Sell 1996). However, we minimized the problem by excluding those who are attracted to both sexes. Finally, we imposed the UNICON age range (30-65 years) to the VM sample. Table A3 in the appendix (Section 6) provides an overview of how we have accomplished a comparison between the surveys.

\subsection{Measures}

We compared socio-demographic characteristics, such as gender (women versus men), age in cohorts, educational level (low (ISCED 0-2), medium (ISCED 3-4), and high (ISCED 5-6)) based on the International Standard Classification of Education (UNESCO 2012), whether a person has children (yes/no), is married (yes/no), and has a paid job (yes/ no). To explore possible interesting outcome variables on which same-sex and mixed-sex couples could potentially differ, we also compared, in the case of mixed-sex couples, church attendance (once a month or more versus rest) and political part preference (Dutch left versus rest). For the comparison of same-sex couples, the variables of neighborhood cohesion (index ranging from 0 indicating low cohesion to 5 indicating high cohesion) and of having been a victim of violence in the last five years (yes/no) have been used. For a detailed overview of the operationalization, see Table A4 in the appendix.

\subsection{Method and Strategy}

As mentioned before, in a first step of evaluating the comparability between the UNICON data and the reference surveys we focus on mixed-sex couples, assuming that if the differences between the samples are not significant, this is at the least a good sign for the same-sex couples in the UNICON data as well. We start with mean comparisons (percent in the UNICON minus percent in the benchmark survey), using the weighted benchmark surveys as a reference for the population we were targeting. On the basis of a t-test it is determined whether the observed difference in means is also statistically significant. This serves as a first crude exploration of possible selectivity of the UNICON sample. However, to determine not only the selectivity patterns of the samples, but also the magnitude of the differences in more detail, we used Average Relative Differences (ARD) (for a comparable application, see Steinmetz et al. 2014). The ARD for the covariate $x$ (with $p$ categories) is defined by $\frac{1}{p} \sum_{j=1}^{p}\left|d_{j}\right|$, where $d_{j}$ is the relative difference for category $\mathrm{j}$, which is defined by 
$d_{j}=\frac{\operatorname{Perc}_{j}^{U N I C O N}-\operatorname{Perc}_{j}^{P O P}}{\operatorname{Perc}_{j}^{U N C O N}}$. The ARD can assume any value between 0 and $+\infty$ In a final step, we examined bivariate associations between possible outcomes of interested and core socio-demographic variables. This is done on the basis of correlation analyses to determine whether similarities or differences (in terms of significance and sign) between the samples could be determined.

\subsection{Results}

\subsubsection{Comparison of Mixed-Sex Couples}

Figure 1 shows the differences in the weighted means for core socio-demographic characteristics, as well as some potential comparable outcome variables (church attendance and party preferences) for mixed-sex couples.

A few differences between the two samples stand out. In the UNICON data, women, people aged 35-39, people who have paid work and people who are married are significantly overrepresented, while people aged 30-34, people with medium education and people with children are underrepresented. A comparison with the ARD (see Table A1 in the appendix) partly confirms the findings of Figure 1. The magnitude of the selectivity seems to be particularly high for age (0.56), education (0.31) and church attendance (0.26), whereas it is lowest for left party preference $(0.05)$.

In a next step, we examined whether similarities and differences between the two samples can be observed when looking at bivariate relationships between possible outcome variables and socio-demographic characteristics (Table 3). This is motivated by the fact that researchers might be interested in using the data beyond purely descriptive purposes (and even extending it to a multivariate framework).

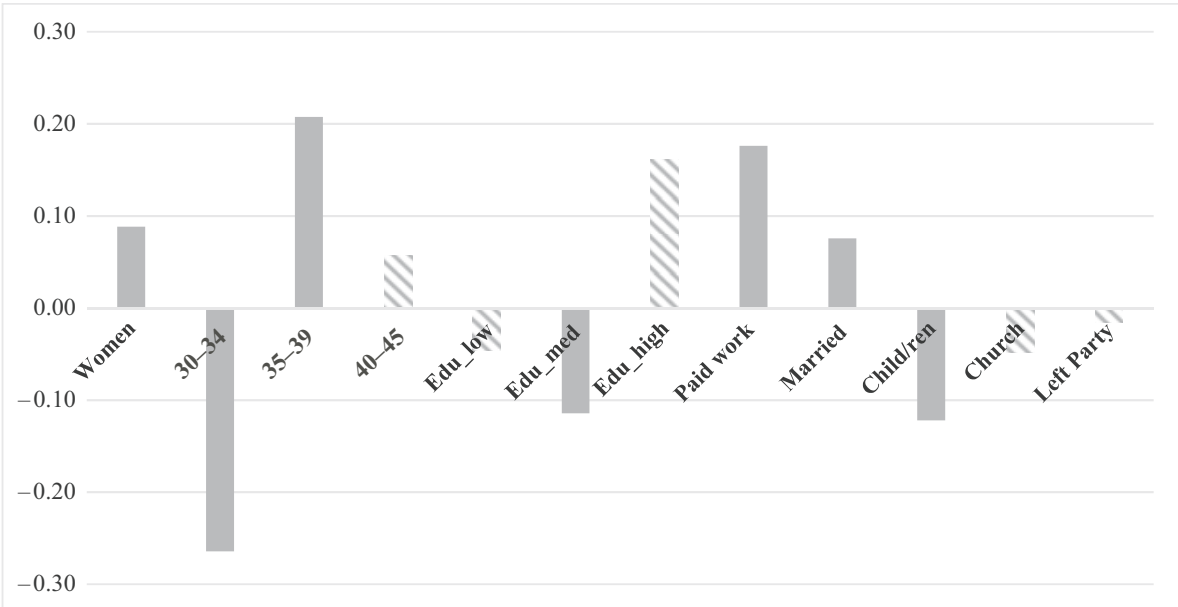

Fig. 1. Weighted mean differences in percent, UNICON versus NELLS data - individuals in mixed-sex couples. Source: UNICON 2016 (N 452) and NELLS 2009 (N 1495), 21 municipalities.

Note: Age is restricted to 30-45 years. Positive values indicate an overrepresentation of the selected characteristics in the UNICON data, whereas a negative values indicates an underrepresentation. The grey bars indicate a significant difference, while the striped bars represent insignificant differences. 
Table 3. Correlation analyses for church attendance and left-party preference, UNICON versus NELLS, persons in mixed-sex couples.

\begin{tabular}{l|cc|cr}
\hline \multirow{2}{*}{} & \multicolumn{2}{|c|}{ Church attendance } & \multicolumn{2}{c}{ Left party preference } \\
\cline { 2 - 5 } & UNICON & NELLS & UNICON & NELLS \\
\hline Women & -0.006 & $-0.178^{* * * *}$ & 0.084 & -0.030 \\
$30-34$ & -0.028 & -0.027 & 0.125 & 0.005 \\
$35-39$ & 0.103 & -0.002 & -0.089 & 0.001 \\
$40-45$ & -0.081 & 0.028 & -0.014 & -0.005 \\
Edu_low & -0.048 & $0.127 * * *$ & $-0.111^{*}$ & -0.015 \\
Edu_med & 0.069 & 0.007 & -0.074 & -0.026 \\
Edu_high & -0.031 & $-0.130^{* * *}$ & $0.140^{* *}$ & 0.042 \\
Paid work & -0.084 & -0.064 & 0.063 & -0.004 \\
Children & 0.053 & $0.138^{* * *}$ & $-0.118^{*}$ & -0.023 \\
Married & $0.171 * * *$ & $0.256 * * *$ & $-0.160 * *$ & 0.015 \\
\hline$N$ & 452 & 1495 & 452 & 1495 \\
\hline
\end{tabular}

Source: UNICON $2016(\mathrm{~N}=452)$ and NELLS $2009(\mathrm{~N}=1495), 21$ municipalities.

$* \mathrm{p}<0.05, * * \mathrm{p}<0.01, * * * \mathrm{p}<0.001$.

Note: Age is restricted to $30-45$ years.

Starting with the correlations for church attendance, besides being married, none of the variables shows a significant correlation within the UNICON sample, whereas in the NELLS data, being a woman, having a low level and high level education, having children and being married is significantly associated with church attendance. The lack of significant correlations in the UNICON data might be attributed to the smaller sample size in comparison to the NELLS data. In addition, only for the variable low education can we observe a divergent sign (negative in UNICON and positive in NELLS) that could hint towards a bias in the UNICON data, where we have a lower share of low-level educated respondents (see Figure 1). Turning to left party preferences, a slightly different picture emerges. While none of the correlations in the NELLS is significant, we can observe four significant correlations within the UNICON (namely for low-level and high-level education, having children and being married). However, as before only one correlation (being married) deviates strongly also in terms of the sign (negative and significant in the UNICON and positive but not significant in the NELLS). Again, this might indicate an underrepresentation of non-married people in the UNICON, which is no surprise given that being a couple was one of our sample criteria.

\subsubsection{Comparison of Same-Sex Couples}

Continuing with the comparison, Figure 2 shows the weighted mean differences for core socio-demographic characteristics, as well as two potential outcome variables (neighborhood cohesion and victim of violence) for same-sex couples. Overall, the results indicate that only for four out of 14 comparison groups, significant differences can be observed. It appears that people with low-level education are underrepresented in the UNICON data, while women, highly educated people and people who have paid work are overrepresented. Also, here a comparison with the ARD (see Table A2 in the appendix) 


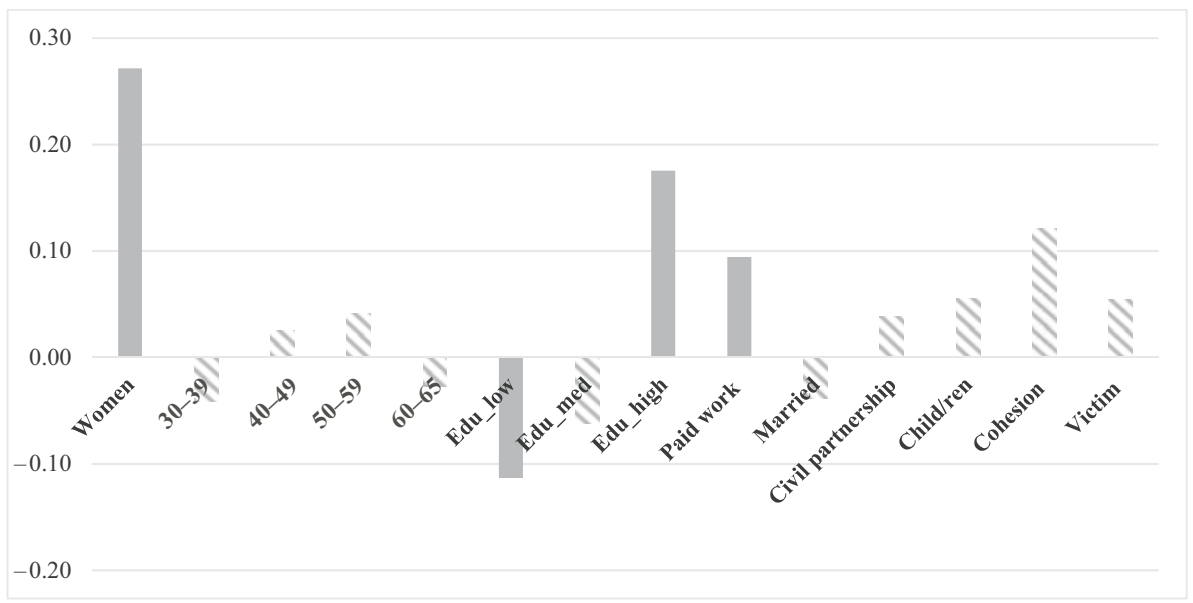

Fig. 2. Weighted mean differences in percent, UNICON versus VM data - persons in same-sex couples. Source: UNICON 2016 (N 452) and VM pooled 2012-2015 (N 355), 16 municipalities.

Note: Positive values indicate an overrepresentation of the selected characteristics in the UNICON data, whereas a negative values indicates an underrepresentation. The grey bars indicate a significant difference, while the striped bars represent insignificant differences.

partly confirms the findings of Figure 2. The magnitude of the selectivity among same-sex couples appears to be particularly high for gender (0.76), being a victim of violence $(0.60)$, and education (0.38), while it is lowest for neighborhood cohesion (0.04).

For the comparison between persons in same-sex relationships, in a final step, we also examined which similarities and differences between the two samples come to the fore when looking at bivariate relationships (Table 4). Starting with the correlation between being a victim of violence and socio-demographic variables, in none of the samples a

Table 4. Correlation analyses for being a victim of violence, UNICON versus. VM, persons in same-sex couples.

\begin{tabular}{l|c|c|c|c}
\hline \multirow{2}{*}{} & \multicolumn{2}{|c|}{ Victim of violence last 5 years } & \multicolumn{2}{c}{ Neighborhood cohesion } \\
\cline { 2 - 5 } & UNICON & VM & UNICON & VM \\
\hline Women & 0.006 & -0.005 & $0.180^{* * *}$ & 0.011 \\
$30-39$ & 0.061 & 0.050 & -0.043 & -0.001 \\
$40-49$ & -0.053 & 0.086 & 0.015 & -0.078 \\
$50-59$ & 0.023 & -0.077 & 0.000 & 0.087 \\
$60-65$ & -0.034 & -0.070 & 0.032 & -0.006 \\
Edu_low & 0.007 & -0.040 & -0.035 & $-0.144^{* *}$ \\
Edu_med & -0.036 & 0.015 & $-0.143^{* * *}$ & -0.078 \\
Edu_high & 0.029 & 0.015 & $0.149^{* * *}$ & $0.176^{* *}$ \\
Paidwork & 0.019 & 0.012 & -0.037 & 0.098 \\
Child/ren & -0.033 & 0.019 & $0.220^{* * *}$ & -0.043 \\
Married & 0.030 & 0.040 & -0.045 & -0.099 \\
Civil partnership & -0.030 & -0.040 & 0.045 & 0.099 \\
\hline$N$ & 585 & 355 & 585 & 355 \\
\hline
\end{tabular}

$* \mathrm{p}<.05, * * \mathrm{p}<.01, * * * \mathrm{p}<.001$. 
significant correlation can be observed. We can see some differences in signs; however, due to the small samples sizes in both cases and the very weak correlations, these deviations can be considered as irrelevant. However, for the variable neighborhood cohesion we find four significant correlations in the UNICON data for being a woman, having a medium-level and high-level education, and having children. For the VM data, we find only two significant correlations, namely for having a low-level and high-level education. This leaves us with only two deviations regarding the significance of the correlations, and we do not find any deviation with respect to the sign. The differences in significance in this case is less related to the difference in the sample size between the samples, but might hint towards selectivity patterns in the two surveys with respect to education (see also Figure 2).

Overall, when examining the representativeness of the UNICON, in particular for the same-sex sample, the observed selectivity seems to be less severe compared with the mixed-sex sample. However, the difference between the UNICON and the NELLS might be related to the fact that the response rate was lowest among persons in mixed-sex relationships in the UNICON (20\%). Therefore, it seems reasonable that we observe some difference. However, it seems difficult to determine the reason for the observed patterns within a sample and the differences across the samples. Even though we have applied sample weights for all analyses, part of the observed selectivity might be the result of different intertwined issues: a) the targeted sampling strategy (with an approximation of household types and an overrepresentation of same-sex households), b) the topic of the survey, which might have been more appealing, for instance, to women and c) to the mode of the survey (web-based) that accommodates the participation of particular respondents.

\section{Discussion and Conclusion}

The present article aimed to answer two core questions in the evaluation process of the recently conducted broadly-oriented probability-based UNICON survey in the Netherlands targeting mixed-sex and same-sex couples with and without children. With respect to the first question - whether our sampling strategy paid off in terms of identifying same-sex households - we can conclude that the strategy was successful. Based on an innovative sampling strategy, we were able to collect a probability survey that allows the comparative analysis of 843 persons in same-sex relationships and 510 persons in mixed-sex relationships.

Regarding our second question - to what extent the collected sample is representative of the target population, we can conclude that, in particular for the UNICON same-sex couple sample - which was our main target - selectivity seems to be reasonably low. The observed difference between the surveys is likely related to the fact that the identification of sexual orientation differs between the two surveys. Regarding the bigger deviations for the mixed-sex couple sample in the UNICON and the NELLS, the low response rate likely has to do with the stronger selectivity pattern. For some of these selectivity patterns, different challenges might be closely related. First, general challenges arise from the web mode of the survey. People who do not have easy access to a computer and the Internet (although Internet penetration rates are high in the Netherlands, $98 \%$ in 2017, see CBS 2018), who are illiterate or do not fully 
master the Dutch language, are by default excluded from participating in the study. Although a web survey might be a good opportunity to receive information on sensitive topics, such as sexual orientation (Villarroel et al. 2006; for a review, see Gribble et al. 1999), we could not reach these nonresponse populations with telephone or face-to-face interviews. Second, nonresponse might be related to the way in which we have framed the main purpose of the study. Participation depends on the personal interest of people in the survey topic (family complexity/diversity in living arrangements) and their motivation to support the research. In particular, LGB populations in the Netherlands are of high interest to researchers and politicians. This can lead to an alertness and sensitization of this group towards any kind of research (phenomenon of an overresearched population). In addition, we also have to recognize that the evaluation of a sample based on a benchmark survey can be challenging in particular when the different modes and measures are used (see Appendix, Table A3). However, in the absence of population information, this can be considered a first step.

Although, we are confident to have collected a quality probability-sample of mixed-sex and same-sex couples in the Netherlands it is important to be aware that those who declined to participate in the UNICON survey might differ in relevant ways from those who did participate (e.g., Tourangeau and Yan 2007). To correct for these biases, additional and more advanced weighting techniques could be applied to adjust the sample to the population of interest. However, new challenges arise with respect to available population benchmarks, particularly for same-sex couples. Biases might also affect the weighted benchmark surveys when it comes to the LGB population. Applied weighting models may be insufficient to alter these biases since they cannot correct the distributions to a sampling frame of LGBs. As long as reliable population information on LGBs and same-sex couples is missing, determining and correcting selection biases of hard-tosurvey groups will remain a challenge.

\section{Appendix}

Table A1. Average relative differences (ARD) between the UNICON and the NELLS data, mixed-sex couples.

\section{ARD}

UNICON versus NELLS

\begin{tabular}{ll}
\hline Age & $\mathbf{0 . 5 6}$ \\
Education & $\mathbf{0 . 3 1}$ \\
Church & $\mathbf{0 . 2 6}$ \\
Paid work & 0.25 \\
Women & 0.19 \\
Child/ren & 0.16 \\
Married & 0.11 \\
Left Party & $\mathbf{0 . 0 5}$ \\
\hline
\end{tabular}

Source: Unicon $2016(\mathrm{~N}=452)$ and NELLS $2009(\mathrm{~N}=1495)$.

Note: Age is restricted to $30-45$ years. 
Table A2. Average relative differences (ARD) between the UNICON and the VM data, samesex couples.

ARD

UNICON versus VM

$\begin{array}{ll}\text { Women } & \mathbf{0 . 7 6} \\ \text { Victim of violence } & \mathbf{0 . 6 0} \\ \text { Education } & \mathbf{0 . 3 8} \\ \text { Child/ren } & 0.18 \\ \text { Married } & 0.17 \\ \text { Age } & 0.15 \\ \text { Paid work } & 0.12 \\ \text { Neighbourhood cohesion } & \mathbf{0 . 0 4}\end{array}$

Source: Unicon $2016(\mathrm{~N}=585)$ and VM pooled 2012-2015 $(\mathrm{N}=355)$.

Note: Age is restricted to $30-45$ years, consideration only of couples who are married and in registered partnerships.

Table A3. Overview of the data sources.

\begin{tabular}{|c|c|c|c|}
\hline \multicolumn{4}{|c|}{ Comparison 1: Mixed-sex couples } \\
\hline & UNICON & NELLS & Comparison \\
\hline $\begin{array}{l}\text { Sexual orientation } \\
\text { measure }\end{array}$ & $\begin{array}{l}\text { Partnership } \\
\text { inferred sexual } \\
\text { orientation }\end{array}$ & $\begin{array}{l}\text { Partnership } \\
\text { inferred sexual } \\
\text { orientation }\end{array}$ & $\begin{array}{l}\text { Mixed-sex } \\
\text { couples only }\end{array}$ \\
\hline Age range & $30-65$ & $15-45$ & $30-45$ \\
\hline Municipalities & 20 & 35 & $\begin{array}{l}19 \text { municipalities } \\
\text { which overlap }\end{array}$ \\
\hline Survey mode & Web mode & Face-to-face & \\
\hline \multicolumn{4}{|c|}{ Comparison 2: Same-sex couples } \\
\hline & UNICON & $\mathrm{VM}$ & Comparison \\
\hline $\begin{array}{l}\text { Sexual orientation } \\
\text { measure }\end{array}$ & $\begin{array}{l}\text { Partnership } \\
\text { inferred sexual } \\
\text { orientation }\end{array}$ & $\begin{array}{l}\text { Attraction inferred } \\
\text { (individuals not } \\
\text { necessarily } \\
\text { partnered) }\end{array}$ & $\begin{array}{l}\text { Limited to same-sex } \\
\text { couples in legally } \\
\text { registered unions }\end{array}$ \\
\hline Age range & $30-65$ & $15+$ & $30-65$ \\
\hline Municipalities & 20 & 35 & $\begin{array}{c}16 \text { municipalities } \\
\text { which overlap }\end{array}$ \\
\hline Survey mode & Web mode & $\begin{array}{l}\text { Web mode and } \\
\text { paper-and-pencil }\end{array}$ & \\
\hline
\end{tabular}




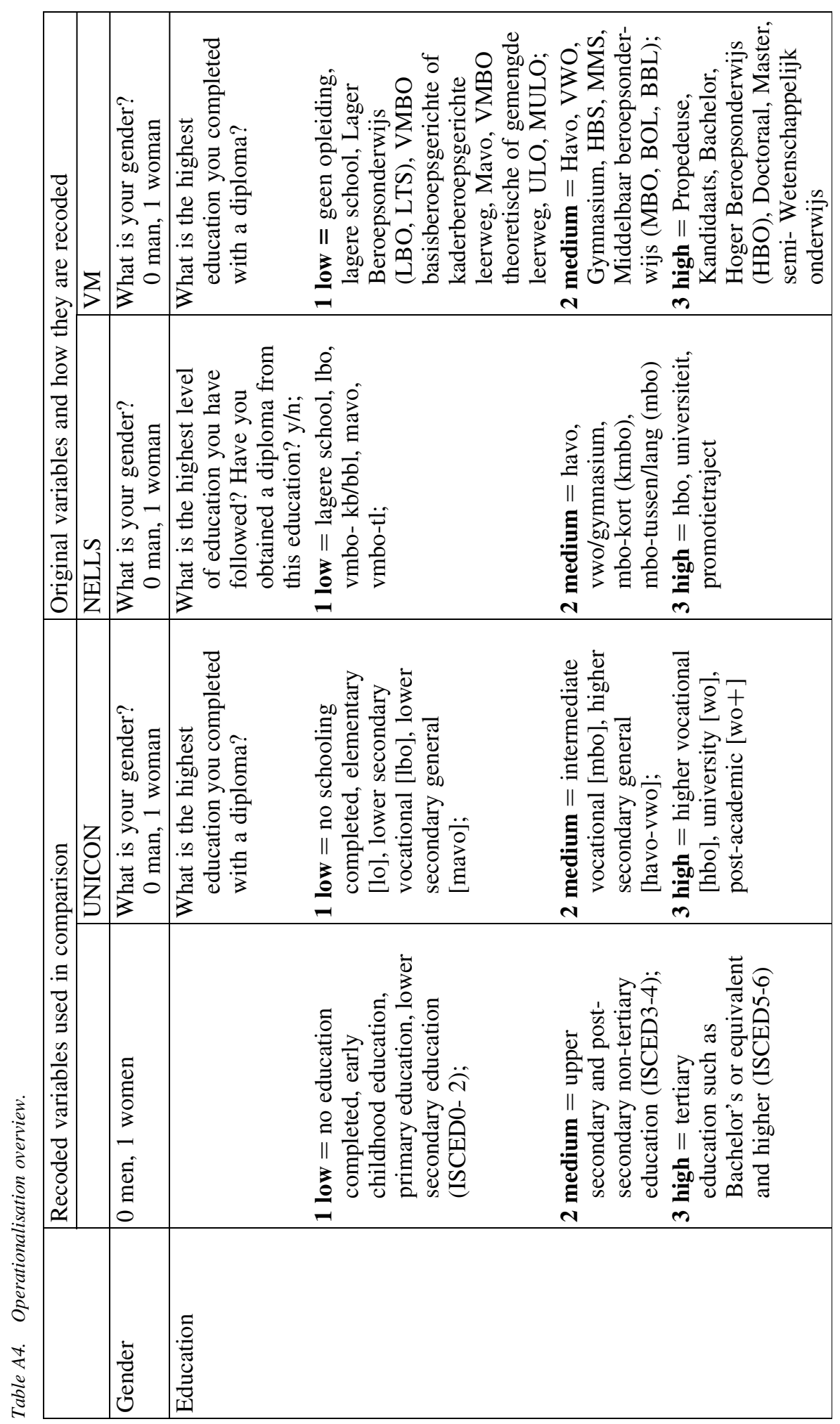




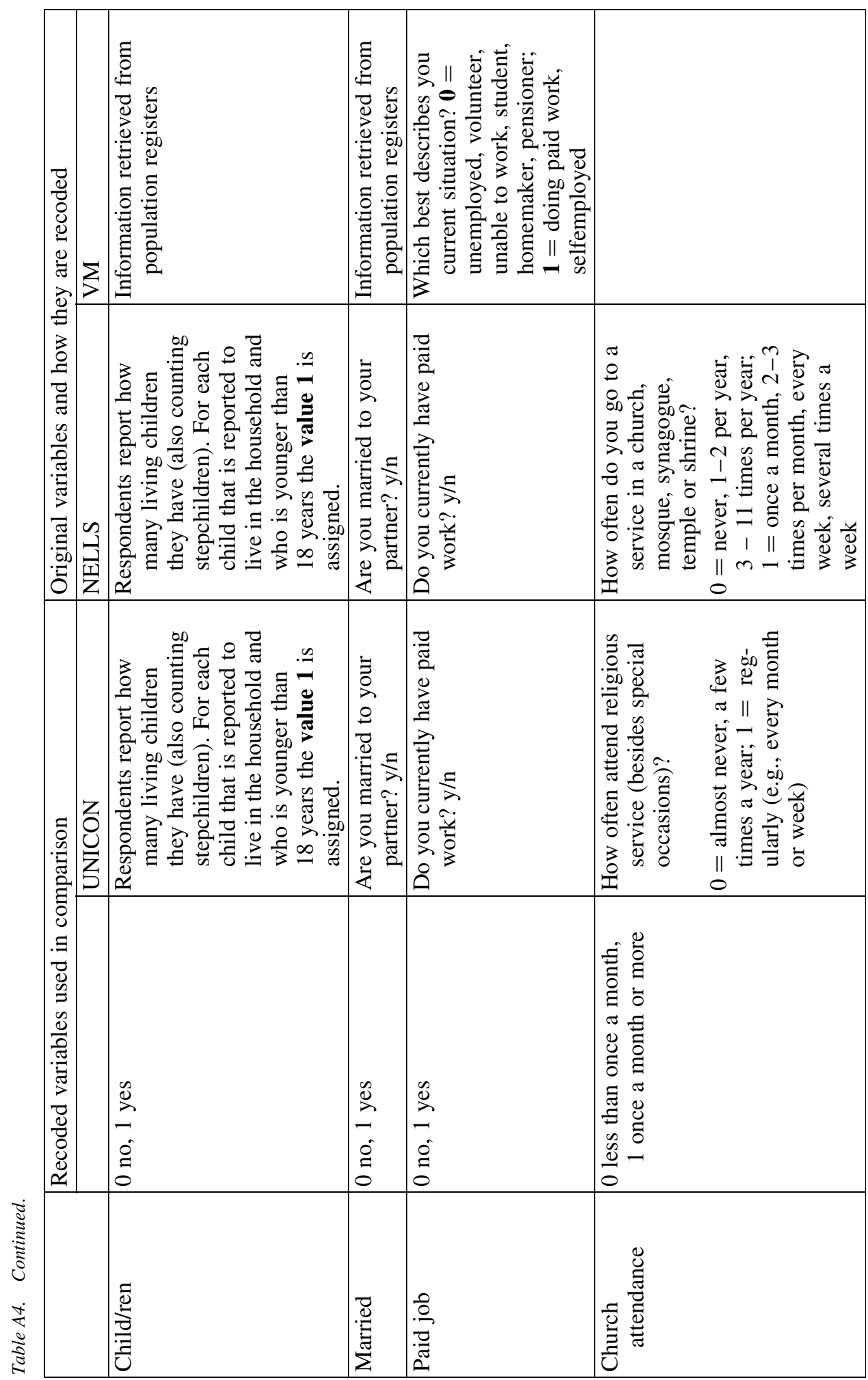




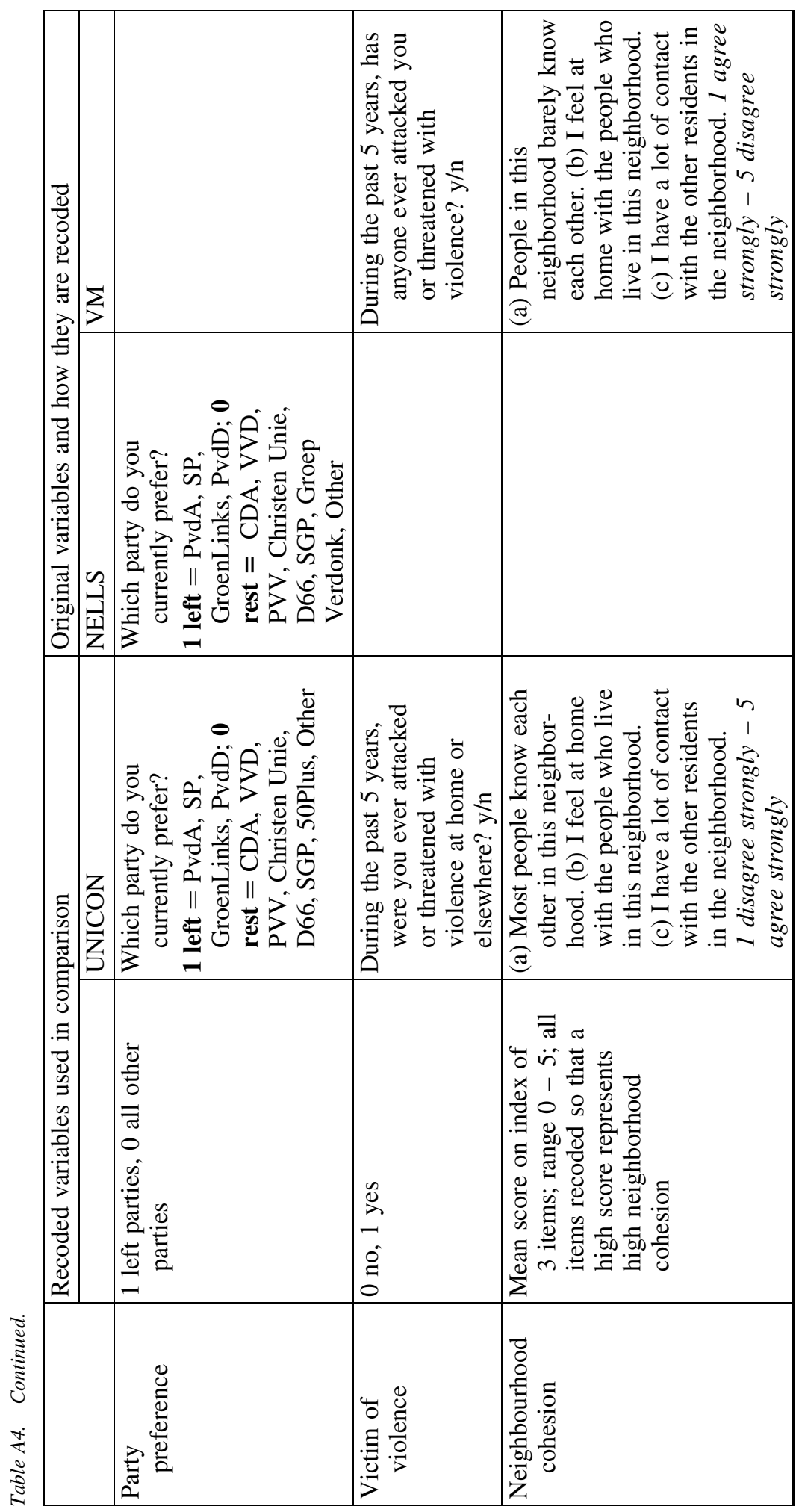




\section{References}

Almazan, E. et al. 2009. "Best Practices for Asking Questions about Sexual Orientation on Surveys?" Los Angeles: The Williams Institute. Available at: https://williamsinstitute. law.ucla.edu/wp-content/uploads/SMART-FINAL-Nov-2009.pdf (accessed September 2019).

Andersson, G., T. Noak, A. Seierstad, and H. Weedon-Fekjaer. 2006. "The demographics of same-sex marriages in Norway and Sweden.” Demography 43: 79-98. DOI: http:// doi.org/10.1353/dem.2006.0001.

Banens, M. and E. Le Penven. 2016. "Sex miscoding in the census and its effects on the enumeration of same-sex couples.” Population 71(1): 131-143. DOI: http://doi.org/10. 3917/popu.1601.0135.

Barrett, H. and F. Tasker. 2001. "Growing up with a gay parent: Views of 101 gay fathers on their sons' and daughters' experiences." Educational and Child Psychology 18: $62-77$.

Bell, A. and M. Weinberg. 1978. “Homosexuality's: a study of diversity among men and women." New York: Simon and Shuster.

Binson, D., J. Blair, D. Huebner, and W. Woods. 2007. Sampling in surveys of lesbian, gay and bisexual people. In The health of sexual minorities: Public health perspectives on lesbian, gay, bisexual and transgender populations, edited by I. Meyer and M. Northridge, 375-418. New York: Springer.

Blair, J. 1999. "A probability sample of gay urban males: The use of two-phase adaptive sampling." The Journal of Sex Research 36: 39-44. DOI: http://doi.org/10.1080/ 00224499909551965.

Bolding, G., M. Davis, G. Hart, L. Sherr, and J. Elford. 2007. "Where young MSM meet their first sexual partner: The role of the Internet." AIDS \& Behavior 11(4): 522-526. DOI: http://doi.org/10.1007/s10461-007-9224-9.

Bos, H. 2004. "Parenting in Lesbian Families." Amsterdam: Amsterdam University Press.

CBS. 2018. "The Netherlands leads Europe in internet access" (press release). Available at: https://www.cbs.nl/en-gb/news/2018/05/the-netherlands-leads-europe-in-internetaccess (accessed September 2019).

Committee on Lesbian, Gay, Bisexual, and Transgender Health Issues and Research Gaps and Opportunities. 2011. "The Health of Lesbian, Gay, Bisexual, and Transgender People: Building a Foundation for Better Understanding. Institute of Medicine (US)." Washington (DC): National Academies Press (US). Available at: https://www.ncbi. nlm.nih.gov/books/NBK64802/.

Conrad, F., M. Couper, R. Tourangeau, and A. Peytchev. 2010. "The impact of progress indicators on task completion." Interacting with Computers 22: 417-427. DOI: http:// doi.org/10.1016/j.intcom.2010.03.001.

Cortina, C. and P. Festy. 2014. "Identification of same-sex couples and families in censuses, registers and surveys." FamiliesAndSocieties Working Papers Series 8. Available at: http://www.familiesandsocieties.eu/wp-content/uploads/2014/12/ WP8CortinaFesty2014.pdf (accessed September 2019). 
De Graaf, P., M. Kalmijn, G. Kraaykamp, and C. Monden. 2010. "Design and content of the NEtherlands Longitudinal Lifecourse Study (NELLS)." Netherlands: Tilburg University \& Radboud University Nijmegen.

DeMaio, T., N. Bates, and M. O'Connell. 2013. "Exploring measurement error issues in reporting same-sex couples." Public Opinion Quarterly 77(Special Issue): 45-158. DOI: http://doi.org/10.1093/poq/nfs066.

Dewaele, A., M. Caen, and A. Buysse. 2014. "Comparing survey and sampling methods for reaching sexual minority individuals in Flanders." Journal of Official Statistics 30(2): 251-275. DOI: http://doi.org/10.2478/jos-2014-0016.

Dillman, D., J. Smyth, and L. Christian. 2009. "Internet, mail, and mixed-mode surveys: The tailored design method (3rd ed.)." New York: John Wiley \& Sons.

ESS, European Social Survey Cumulative File, ESS 1-8. 2018. Data file edition 1.0. NSD - Norwegian Centre for Research Data, Norway - Data Archive and distributor of ESS data for ESS ERIC. DOI: http://doi.org/10.21338/NSD-ESS-CUMULATIVE.

European Union Agency for Fundamental Rights. 2012. "EU LGBT survey - Technical report Methodology, online survey, questionnaire and sample." Research report. Available at: http://fra.europa.eu/en/survey/2012/eu-lgbt-survey (accessed September 2019).

Evans, A., R. Wiggins, G. Bolding, and J. Elford. 2008. "Characteristics of gay and bisexual men who drop out of a web survey of sexual behaviour in the UK." AIDS \& Behavior 12(6): 957-963. DOI: http://doi.org/10.1007/s10461-008-9400-6.

Fischer, M. 2016. "Identifying same-sex couples in cross-national survey data: A comparison of same-sex couples' demographic and socio-economic traits in six European countries." In Nederland in context: verschillen en overeenkomsten, edited by R. Meuleman, G. Kraaykamp, and M. Wittenberg, 50-79. Den Haag: DANS.

Fischer, M. 2019. "Free to Live their Lives as they Wish? The Social Well-Being Gap between Persons in Same-Sex and Mixed-Sex Relationships in Europe" [Doctoral dissertation]. University of Amsterdam: The Netherlands. ISBN 978-94-92679-72-7.

Fischer, M. and S. Steinmetz. 2018. "Designing a Sampling Frame for Same-Sex Couples and Families: The Unions in Context Study" In SAGE Research Methods. Cases (Vol. 2). London: SAGE.

Fischer, M., M. Kalmijn, and S. Steinmetz. 2017. "Design, content and questionnaire of the UNICON study: Lesbian, gay and heterosexual couples and families in the Netherlands." Research report. University of Amsterdam, the Netherlands. Available at: https://dare.uva.nl/search?identifier $=$ d7a835f9-7c1b-448b-8047-a9779f5710db (accessed September 2019).

Galupo, M., E. Lomash, and R. Mitchell. 2016. "All of my lovers fit into this scale: sexual minority individuals' responses to two novel measures of sexual orientation." Journal of Homosexuality 64: 145-165. DOI: http://doi.org/10.1080/00918369.2016.1174027.

Gates, G. 2013. "LGBT Parenting in the United States." Los Angeles, CA: Williams Institute, UCLA School of Law. Available at: http://williamsinstitute.law.ucla.edu/ wp-content/uploads/LGBT-Parenting.pdf.

GGS Waves 1, and 2. DOI: http://doi.org/10.17026/dans-z5z-xn8g, and http://doi.org/10. 17026/dans-xm6-a262. 
Goldberg, A. and K. Allen. 2007. "Lesbian mothers' ideas and intentions about male involvement across the transition to parenthood." Journal of Marriage and Family 69: 352-365. DOI: http://doi.org/10.1111/j.1741-3737.2007.00370.x.

Gribble, J., H. Miller, S. Rogers, and C. Turner. 1999. "Interview mode and measurement of sexual behaviors: Methodological issues." Journal of Sex Research 36(1): 16-24. DOI: https://doi.org/10.1080/00224499909551963.

Haseldon, L. and T. Joloza. 2009. "Measuring sexual identity: a guide for researchers." Newport (UK): Office for National Statistics. Available at: https://www.ons.gov.uk/ methodology/classificationsandstandards/sexualidentityguidanceandprojectdocumentation (accessed November 2019).

Herek, G., A. Norton, T. Allen, and C. Sims. 2010. "Demographic, psychological, and social characteristics of self-identified lesbian, gay, and bisexual adults in a US probability sample." Sexuality Research and Social Policy 7(3): 176-200. DOI: http:// doi.org/10.1007/s13178-010-0017-y.

Hicks, S. 2005. 'Is gay parenting bad for kids? Responding to the 'very idea of difference' in research on lesbian and gay parents." Sexualities 8: 153-168. DOI: http://doi.org/10. $1177 / 1363460705050852$.

Institute of Medicine (US) Committee on Lesbian, Gay, Bisexual, and Transgender Health Issues and Research Gaps and Opportunities. 2011. "The Health of Lesbian, Gay, Bisexual, and Transgender People: Building a Foundation for Better Understanding." Washington (DC): National Academies Press (US). Available at: https:// www.ncbi.nlm.nih.gov/books/NBK64802/.

Kenyon, E. and S. Heath. 2010. "Choosing this life: narratives of choice amongst house sharers." Housing Studies 16(4): 619-635. DOI: http://doi.org/10.1080/026730301 20080080.

Kinsey, A., W. Pomeroy, and C. Martin. 1948. "Sexual Behaviour in the Human Male." Philadelphia: Saunders.

Kuyper, L. 2016. "LHBT-monitor 2016: opvattingen over en ervaringen van lesbische, homoseksuele, biseksuele en transgender personen.” Den Haag: Sociaal en Cultureel Planbureau.

Laumann, E., J. Gagnon, R. Michael, and S. Michaels. 1994. "The social organization of sexuality: Sexual practices in the United States." Chicago: The University of Chicago Press.

Lee, R. 1993. "Doing research on sensitive topics." London: Sage Publications.

Lozar Manfreda, K., M. Bosnjak, J. Berzelak, I. Haas, and V. Vehovar. 2008. "Web surveys versus other survey modes: A meta-analysis comparing response rates." International Journal of Market Research 50(1): 79-104. DOI: http://doi.org/10.1177/ 147078530805000107.

Meyer, I. and M. Colten. 1999. "Sampling gay men: Random Digit Dialing versus sources in the gay community." Journal of Homosexuality 37(4): 99-110. DOI: http://doi.org/ 10.1300/J082v37n04_06.

Meyer, I. and P. Wilson. 2009. "Sampling lesbian, gay, and bisexual populations." Journal of Counseling Psychology 56(1): 23-31. DOI: http://doi.org/10.1037/a0014587.

Muñoz-Leiva, F., J. Sánchez-Fernández, F. Montoro-Ríos, and J. Ibáñez-Zapata. 2010. "Improving the response rate and quality in Web-based surveys through the 
personalization and frequency of reminder mailings." Quality \& Quantity 44(5): 1037-1052. DOI: http://doi.org/10.1007/s11135-009-9256-5.

OECD. 2019. "Society at a Glance 2019: OECD Social Indicators." Paris: OECD Publishing. DOI: https://doi.org/10.1787/soc_glance-2019-en.

Patterson, C. 1992. "Children of lesbian and gay parents." Child Development 63: 1025-1042. DOI: http://doi.org/10.2307/1131517.

Régnier-Loilier, A. 2018. "Are the Generations and Gender Surveys well suited for studying same-sex couples?" European Journal of Population 34(4): 567-578. DOI: http://doi.org/10.1007/s10680-017-9440-6.

Rosser, B., M. Miner, W. Bockting, M. Ross, J. Konstan, L. Gurak, J. Stanton, W. Edwards, S. Jacoby, A. Carballo-Dieguez, R. Mazin, and E. Coleman. 2009. "HIV risk and the Internet: Results of the Men's Internet Sex (MINTS) Study." AIDS \& Behavior 13(4): 746-756. DOI: http://doi.org/10.1007/s10461-008-9399-8.

Ross, M., B. Rosser, and J. Stanton. 2004. "Beliefs about cybersex and Internet-mediated sex of Latino men who have Internet sex with men: Relationships with sexual practices in cybersex and in real life." AIDS Care 16(8): 1002-1011. DOI: http://doi.org/10. 1080/09540120412331292444.

Rothblum, E. 2007. "From science fiction to computer-generated technology: Sampling lesbian, gay, and bisexual individuals." In The health of sexual minorities: Public health perspectives on lesbian, gay, bisexual and transgender populations, edited by I. Meyer and M. Northridge, 441-454. New York: Springer.

Schwartz, C. and N. Graf. 2009. "Assortative matching among same-sex and different-sex couples in the United States, 1990-2000.” Demographic Research 21: 843-878. DOI: http://doi.org/10.4054/DemRes.2009.21.28.

Sell, R. and C. Petrulio. 1996. "Sampling homosexuals, bisexuals, gays, and lesbians for public health research: A review of the literature from 1990 to 1992." Journal of Homosexuality 30(4): 31-47. DOI: http://doi.org/10.1300/J082v30n04_02.

Smyth, J. and J. Pearson. 2011. "Internet survey methods: A review of strengths, weaknesses, and innovations." In Social and behavioral research and the internet. Advances in applied methods and research strategies, edited by M. Das, P. Ester, and L. Kaczmirek, 11-44. New York, NY: Routledge.

Solarz, A. (ed.). 1999. "Lesbian health: current assessment and directions for the future." Washington, DC: National Academy Press.

Sudman, S., M. Sirken, and C. Cowan. 1988. "Sampling rare and elusive populations." Science 240: 991-996. DOI: https://doi.org/10.1126/science.240.4855.991.

Spira, A., N. Bajos, and the ACSF Group. 1994. "Sexual Behaviour and AIDS." Aldershot, England: Avebury.

Statistics Netherlands. 2016. "Veileigheidsmonitor 2015." Research report. Den Haag, the Netherlands. Available at: https://download.cbs.nl/pdf/veiligheidsmonitor-2015.pdf (accessed November 2019).

Statistics Netherlands. 2018. "Population dynamics; birth, death and migration per region.” Available at: https://opendata.cbs.nl/statline/\#/CBS/en/dataset/37259eng/ table?dl=1310C (accessed November 2019). 
Tolsma, J., G.L.M. Kraaykamp, P.M. de Graaf, M. Kalmijn, C.M. Monden. 2014. Netherlands Longitudinal Lifecourse Study - NELLS Panel Wave 12009 and Wave 2 2013 - versie 1.2. DANS. DOI: https://doi.org/10.17026/dans-25n-2xjv.

Tourangeau, R. and T. Yan. 2007. "Sensitive questions in surveys." Psychological Bulletin 133(5): 859-883. DOI: http://doi.org/0.1037/0033-2909.133.5.859.

Tourangeau, R. 2014. "Defining hard to survey populations." In Hard to Survey Populations, edited by B. Edwards, R. Tourangeau, T. Johnson, K. Wolter, and N. Bates, 3-21. Cambridge University Press.

Shih, T.-H. and X. Fan. 2008. "Comparing response rates from Web and mail surveys: A metaanalysis." Field Methods 20(3): 249-271. DOI: http://doi.org/10.1177/ 1525822 X08317085.

Umberson, D., M. Thomeer, P. Kroeger, A. Lodge, and M. Xu. 2015. "Challenges and opportunities for research on same-sex relationships." Journal of Marriage and Family 77(1): 96-111. DOI: http://doi.org/10.1111/jomf.12155.

UNESCO. 2012. "International Standard Classification of Education ISCED 2011." UNESCO Institute for Statistics, Canada. Available at: http://uis.unesco.org/sites/ default/files/documents/international-standard-classification-of-education-isced-2011en.pdf (accessed September 2019).

Wellings, K., J. Field, A. Johnson, and J. Wadsworth. 1994. "Sexual Behaviour in Britain: The National Survey of Sexual Attitudes and Lifestyles." London: Penguin Books.

Wolff, M., B. Wells, C. Ventura-DiPersia, A. Renson, and C. Grov. 2017. "Measuring sexual orientation: a review and critique of U.S. data collection efforts and implications for health policy." The Journal of Sex Research 54: 507-553. DOI: http://doi.org/10. 1080/00224499.2016.1255872.

Valfort, M.-A. 2017. "LGBTI in OECD Countries: A Review." OECD Social, Employment and Migration Working Papers, OECD Publishing, Paris. Available at: https://doi.org/10.1787/d5d49711-en (accessed June 2019).

Villarroel, M., C. Turner, E. Eggleston, A. Al-Tayyib, S. Rogers, A. Roman, P. Cooley, and H. Gordek. 2006. "Same-gender sex in the United States: Impact of T-ACASI on prevalence estimates.” Public Opinion Quarterly 70(2): 166-196. DOI: http://doi.org/ $10.1093 / \mathrm{poq} / \mathrm{nfj} 023$.

Received June 2018

Revised June 2019

Accepted September 2019 